\title{
Adipsic diabetes insipidus and venous thromboembolism (VTE): recommendations for addressing its hypercoagulability
}

\author{
Dragana Miljic, ${ }^{1}$ Predrag Miljic, ${ }^{2}$ Mirjana Doknic, ${ }^{1}$ Sandra Pekic, ${ }^{1}$ Marko Stojanovic, ${ }^{3}$ \\ Milan Petakov, ${ }^{1}$ Vera Popovic ${ }^{1}$
}

${ }^{1}$ Clinic of Endocrinology, ${ }^{2}$ Clinic of Hematology; Medical Faculty, Belgrade University, Clinical Center of Serbia; ${ }^{3}$ Clinic of Endocrinology, Clinical Center of Serbia; Belgrade, Serbia

\begin{abstract}
Adipsic diabetes insipidus (ADI) is a rare disorder. It can occur after transcranial surgery for craniopharyngeoma, suprasellar pituitary adenoma and anterior communicating artery aneurysm but also with head injury, toluene exposure and developmental disorders. It is often associated with significant hypothalamic dysfunction and complications like obesity, sleep apnea, thermoregulatory disorders, seizures and venous thromboembolism (VTE). Morbidity and mortality data have been reported as single case reports with only one large series suggesting increased risk for VTE in patients with ADI. Here we report a mini-series of four patients with ADI and VTE. Post-surgery immobilization, obesity, infection, with prolonged hospitalization, hemoconcentration and changes in coagulation which might be induced by inadequate hormone treatment in the postoperative period (high doses of glucocorticoids, sex steroids and DDAVP replacement) may all contribute to the pathogenesis of VTE. Thromboprophylactic treatment after pituitary surgery and during episodes of hypernatremia is therefore warranted.
\end{abstract}

Key words: Adipsia, Diabetes insipidus, Thrombosis

\section{INTRODUCTION}

Although diabetes insipidus is a common complication of pituitary surgery, adipsic diabetes insipidus (ADI) is very rare. It can occur after extensive transcranial surgery for craniopharyngeoma, ${ }^{1}$ germinoma ${ }^{2}$ and pituitary macroadenoma, ${ }^{3}$ clipping of anterior communicating artery aneurysm, ${ }^{4}$ but also with head

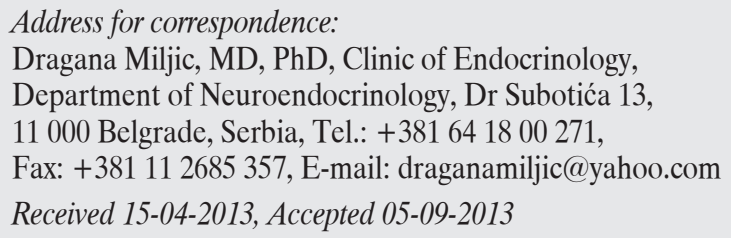

injury, ${ }^{5}$ toluene exposure, ${ }^{6}$ neurosarcoidosis ${ }^{7}$ and developmental disorders. ${ }^{8-10}$ Impaired sense of thirst and vasopressin (AVP) secretion put these patients at risk of severe dehydration and hypernatremia. One of the potentially fatal but preventable complications in this setting is venous thromboembolism (VTE). VTE has been described previously in these patients but literature data are scarce due to the rarity of the disorder. So far, morbidity and mortality data have been derived from single case reports with only one large series of 13 patients, four with VTE, suggesting increased risk for thromboembolic complications and mortality in these patients. ${ }^{7}$ Here we report four 
patients with ADI who developed thromboembolic complications during episodes of hypernatremia after pituitary surgery. Furthermore, we discuss several situations which can aggravate hypercoagulability in this setting.

\section{Patient cohort}

The four patients reported in this paper presented between 1995 and 2010. They were referred for further treatment to the Neuroendocrine Department of the Clinical Center of Serbia after developing ADI following surgical resection of a nonfunctioning pituitary macroadenoma (NFPA, one patient) and craniopharyngeoma (three patients). Clinical features and hormonal and electrolyte status are presented in Table 1. None of our patients presented with diabetes insipidus initially. In two patients panhypopituitarism was diagnosed on presentation, while two presented with secondary hypogonadism and developed panhy- popituitarism after pituitary surgery. Free thyroxine (FT4), thyroid stimulating hormone (TSH), gonadotropins, testosterone/estradiol, cortisol and insulin like growth factor 1 (IGF-1) were measured in all patients upon presentation and three months after the pituitary surgery using commercially available kits. For the purpose of this paper, informed consent was obtained from the patients and their medical histories were analyzed retrospectively.

\section{RESULTS}

In all four patients, $\mathrm{ADI}$ developed after the second pituitary surgery for tumor remnants adherent to the hypothalamus and optic chiasm. ADI was diagnosed in the postoperative period on the basis of severe hypernatremia, hyperosmolar state and hypotonic polyuria (Table 1). All patients demonstrated no desire to drink despite being conscious and dehy-

Table 1. Clinical and biochemical features of patients with adipsic diabetes insipidus and venous thromboembolism before and after pituitary surgery

\begin{tabular}{|c|c|c|c|c|}
\hline Parameter & Patient 1 & Patient 2 & Patient 3 & Patient 4 \\
\hline Gender & Male & Female & Male & Male \\
\hline Age & 27 & 23 & 20 & 50 \\
\hline Diagnosis & $\begin{array}{l}\text { Nonfunctioning } \\
\text { pituitary adenoma }\end{array}$ & Craniopharyngeoma & Craniopharyngeoma & Craniopharyngeoma \\
\hline $\begin{array}{l}\text { Presenting signs \& symptoms } \\
\text { (before surgery) }\end{array}$ & $\begin{array}{l}\text { Headache, visual } \\
\text { impairment }\end{array}$ & $\begin{array}{c}\text { Headache, } \\
\text { visual impairment, } \\
\text { secondary amenorrhea }\end{array}$ & $\begin{array}{l}\text { Visual impairment, } \\
\text { arrested puberty }\end{array}$ & $\begin{array}{c}\text { Lethargy, } \\
\text { depression, } \\
\text { visual impairment }\end{array}$ \\
\hline $\begin{array}{l}\text { Endocrine status } \\
\text { (before surgery) }\end{array}$ & $\begin{array}{c}\text { Secondary } \\
\text { hypogonadism }\end{array}$ & Panhypopituitarism & Panhypopituitarism & $\begin{array}{c}\text { Secondary } \\
\text { hypogonadism }\end{array}$ \\
\hline $\begin{array}{l}\text { Serum sodium (mmol/l) } \\
\text { (before surgery) }\end{array}$ & 140 & 140 & 142 & 139 \\
\hline $\begin{array}{l}\text { Serum sodium }(\mathrm{mmol} / \mathrm{l}) \\
\text { (after } 2^{\text {nd }} \text { surgery) }\end{array}$ & 168 & 165 & 171 & 166 \\
\hline $\begin{array}{l}\text { Daily diuresis (L) } \\
\text { (after } 2^{\text {nd }} \text { surgery) }\end{array}$ & $9-10$ & 6 & 8 & $5-6$ \\
\hline $\begin{array}{l}\text { Serum osmolality (mosmol } / \mathrm{kg}) \\
\text { (after } 2^{\text {nd }} \text { surgery) }\end{array}$ & 324 & 310 & 343 & 312 \\
\hline $\begin{array}{l}\text { Urine osmolality (mosmol/kg) } \\
\text { (after } 2^{\text {nd }} \text { surgery) }\end{array}$ & 283 & 280 & 292 & 206 \\
\hline Sense of thirst (after $2^{\text {nd }}$ surgery) & No & No & No & No \\
\hline $\begin{array}{l}\text { Venous thrombo-embolism } \\
\text { (after } 2^{\text {nd }} \text { surgery) }\end{array}$ & Yes & Yes & Yes & Yes \\
\hline Comorbidities (after $2^{\text {nd }}$ surgery) & Obesity, hydrocephalus & Epilepsy & Obesity, sleep apnea & Hydrocephalus \\
\hline
\end{tabular}


drated. The sense of thirst did not recover during the long-term follow-up (3-17 years). They received 1-thyroxine and hydrocortisone replacement for hypopituitarism and were managed with intravenous fluids and desmopressin acetate (DDAVP). Electrolyte and water balance were monitored closely. Sex steroid replacement was omitted in the perioperative period. None of the patients received replacement for growth hormone deficiency. In the first two weeks after pituitary surgery, all patients developed deep venous thrombosis (DVT) in the lower extremities and were treated with low-molecular-weight heparin. Diagnosis of DVT was made on the basis of clinical signs, confirmed by Doppler ultrasound examination and elevated D-dimmer levels. Pulmonary embolism was registered in two patients. Past medical and family history of our patients was negative for thrombosis. Clinical and biochemical features in the postoperative period are presented in Table 1.

\section{DISCUSSION}

Adipsic diabetes insipidus is a rare disorder associated with significant morbidity and mortality rates. Our case series emerged from the clinical observation that these patients often suffer from venous thromboembolic complications in the postoperative period when hypernatremia and dehydration develop. Crowley and colleagues were the first to report the increased incidence of venous thromboembolism in adult patients with ADI. Four out of 13 patients from their study developed VTE and two of those patients died. ${ }^{7}$ Previously, VTE has been reported only in animal models of hypernateremia ${ }^{11}$ and pediatric patients with ADI. ${ }^{12}$

Surgery, immobilization, obesity, infection, hemoconcentration during episodes of hypernatremia and coagulation changes (release of factor VIII (FVIII) and von Willebrand factor (VWF) from the endothelium, induced by DDAVP treatment) may contribute to the pathogenesis of VTE and prolonged hospitalization of these patients. Although DDAVP doses for bleeding are up to 10-fold higher than doses used for diabetes insipidus, Crescenzi and colleagues showed in their meta-analysis that prophylactic use of desmopressin acetate in the perioperative period slightly reduced blood loss and transfusion require- ments without a statistically significant increase in thromboembolic adverse events. ${ }^{13}$ However, in patients with $\mathrm{ADI}$, special considerations regarding potentially reversible aggravating factors for hypercoagulability (dehydration, sex steroid replacement, high dose glucocorticoid replacement in the perioperative period and secondary polycythemia in patients with sleep apnea) should be made and thromboprophylaxis with low-molecular-weight heparin applied. In our 27-yearold male patient, who developed massive pulmonary infarction, hereditary and acquired thrombophilia were tested and excluded, suggesting that hemoconcentration and immobilization were the main causes of hypercoagulability. Similar hypercoagulability and risk of VTE in the postoperative period can be observed in patients operated on for Cushing's disease, in whom thromboprophilaxis is also advised. ${ }^{14}$

The majority of our patients were operated on for craniopharyngeoma and only one for suprasellar NFPA. Diabetes insipidus (80-90\%) and abnormalities of thirst $(7-12 \%)$ are well documented in both adult and pediatric series of patients with craniopharyngeomas compared to $30 \%$ of DI after suprasellar adenomectomy. ${ }^{15,16}$ It has been shown that in these patients ADI is usually associated with severe hypothalamic dysfunction (obesity, sleep apnea, thermoregulatory disorders, epilepsy) and impaired vasopressin response to both osmotic and hypotensive stimuli, compared to patients with other causes of ADI, who have preserved baroregulation of vasopressin response. ${ }^{17,18}$ This suggests that the size of the lesion is more marked in craniopharyngeoma patients than in those with ADI from other causes. The impaired vasopressin response to hypotension and hypovolemia may further increase the likelihood of hospital admissions due to hypernatremia in patients with craniopharyngeomas.

Recently, Sinha et al, have shown the recovery of thirst perception in three pediatric craniopharyngeoma patients with adipsia, within 9 months of surgery, despite persistence of central diabetes insipidus. ${ }^{19}$ These findings suggest more plasticity in the osmoreceptors (capacity for recovery and regeneration) compared to the damaged pituitary stalk and centers for vasopressin production. These data are promising in the sense that a time-consuming regimen for remaining eunatremia in these patients can eventually be re- 
laxed. However, the authors doubted the likelihood of thirst recovery beyond the first year after surgery in their pediatric patients and we did not observe thirst recovery in our adult patients with ADI during the long-term follow-up (up to 17 years).

Awareness of VTE and increased morbidity and mortality are needed in patients with ADI since some of these potentially fatal comorbidities can be prevented. Thromboprophylactic treatment with low-molecular-weight heparin after pituitary surgery and during episodes of hypernatremia is warranted in these patients. Special considerations regarding sex steroid replacement and secondary polycythemia in patients with sleep apnea are also suggested in some obese patients.

\section{ACKNOWLEDGEMENTS}

Supported by Research Grant No. 175033 of the Ministry of Science of the Republic of Serbia.

\section{CONFLICT OF INTEREST STATEMENT}

The authors have no conflict of interest to declare.

\section{REFERENCES}

1. Smith D, McKenna K, Moore K, et al, 2002 Baroregulation of vasopressin release in adipsic diabetes insipidus. J Clin Endocrinol Metab 87: 4564-4568.

2. Arai K, Akimoto H, Inokami T, et al, 1999 Marked hypernatremia in suprasellar germinoma lacking a sense of thirst. Nihon Jinnzo Gakkai Shi 41: 804-812.

3. Sherlock M, Agha A, Crowley R, Smith D, Thompson CJ, 2006 Adipsic diabetes insipidus following pituitary surgery for a macroprolactinoma. Pituitary 9: 59-64.

4. McIver B, Connacher A, Whittle I, Baylis P, Thompson CJ, 1991 Adipsic hypothalamic diabetes insipidus after clipping of anterior communicating artery aneurysm. BMJ 303: 1465-1467.

5. Thompson CJ, Baylis PH, 1987 Thirst in diabetes insipidus: clinical relevance of quantitative assessment. Quart J Med 65: 853-862.

6. Teelucksingh S, Steer CR, Thompson CJ, Seckl JR, Douglas NJ, Edwards CR, 1991 Hypothalamic syndrome and central sleep apnea associated with toluene exposure. Quart J Med 78: 185-190.

7. Crowley RK, Sherlock M, Agha A, Smith D, Thompson CJ, 2007 Clinical insights into adipsic diabetes insipidus: a large case series. Clin Endo 66: 475-482.

8. Ronconi GF, Ronconi M, Stella M, Soffiati G, Pesenti P, 1985 Neurogenic hypernatremia with adipsia and cerebral malformations in a child with ectrodactylyectodermal dysplasia-cleft-lip-palate syndrome. Pediatr Med Chir 7: 893-897.

9. Steinbrugger B, Kurz R, 1983 "Essential hypernatremia" as a result of an increased osmoreceptor threshold in a boy with Pierre-Robin disease and corpus callosum agenesis. Padiatr Padol 18: 181-185.

10. Komatsu H, Miyake H, Kakita S, Ikuta H, 2001 Hypoplasia of the corpus callosum associated adipsic hypernatremia and hypothalamic hypogonadotropism: a case report and review of the literature. Pediatr Int 43: 683-687.

11. Harber E.S, O’Sullivan MG, Jayo MJ, Carlson CS, 1996 Cerebral infarction in two cynomolgus macaques (macaca fascicularis) with hypernathremia. Vet Pathol 33: 431-434.

12. Bergada I, Aversa L, Heinrich JJ, 2004 Peripheral venous thrombosis in children and adolescents with adipsic hypernatremia secondary to hypothalamic tumors. Horm Res 61: 108-110.

13. Cresenzi G, Landoni G, Biondi-Zoccai G, et al, 2008 Desmopressin reduces transfusion needs after surgery: a meta-analysis of randomized clinical trials. Anesthesiology 109: 1063-1076.

14. Miljic P, Miljic D, Cain JW, Korbonits M, Popovic V, 2012 Pathogenesis of vascular complications in patients with Cushing's syndrome. Hormones (Athens) 11: 19-28.

15. Crowley RK, Hamnvik OP, O'Sullivan EP, et al, 2010 Morbidity and mortality in patients with craniopharyngeoma after surgery. Clin Endocrinol 73: 516-521.

16. Hannon MJ, Finucane FM, Sherlock M, Agha A, Thompson CJ, 2012 Disorders of water homeostasis in neurosurgical patients. J Clin Endocrinol Metab 97: 1423-1433.

17. Smith D, McKenna K, Moore K, et al, 2002 Baroregulation of vasopressin release in adipsic diabetes insipidus. J Clin Endocrinol Metab 87: 4564-4568.

18. Smith D, Finucane F, Phillips J, et al, 2004 Abnormal regulation of thirst and vasopressin secretion following surgery for craniopharyngeoma. Clin Endocrinol 61: 273-279.

19. Sinh A, Ball S, Jenkins A, Hale J, 2011 Objective assessment of thirst recovery in patients with adipsic diabetes insipidus. Pituitary 14: 307-311. 